\title{
Relationship between the Curves of Spee in Persons with Normal Occlusion and the Occlusal Plane (Abstract)
}

\author{
by \\ Masatoshi ARITA, Tadamasa IWASAWA and Shinkichi NAMURA
}

It is a well-known fact that in 1890 Spee of Germany propounded his theory that came to be accepted as the curve of Spee and it is regarded as one of the most major items in the field of dental prosthetics. Importance of the curve of Spee is also recognized in orthodontia in connection with diagnosis of vertical irregularities in the teeth or arch but a definitive study on the curve of Spee in the Japanese is yet to be undertaken.

In the present paper the authors are concerned with determination of degree as to the curves of Spee in the selected number of Japanese who have the normal occlusion.

As the subject materials use was made of plaster models of 11 male and 19 female Japanese collected and housed by the Department of Orthodontics, Nihon University School of Dentistry. The models were subjected to the following criteria.

1. Establishment of an imaginary occlusal plane.

As imaginary occlusion, two planes were initially established. One is a plane extending from the tip of the lower central incisor to the distal buccal cusp of the lower second molar and the other extending from the tip of the lower central incisor to the distal buccal cusp of the lower first molar (Fig. 1).

Fig. 1

Imaginary occlusal plane
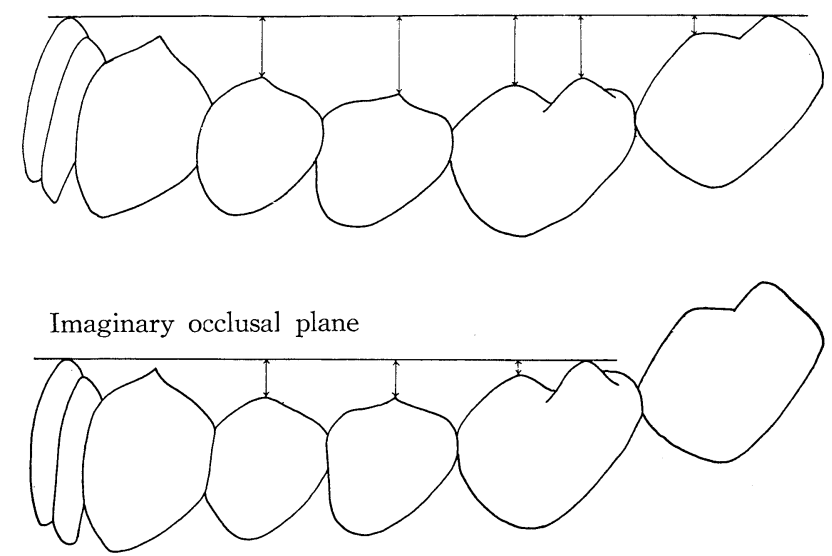

有田 正俊, 岩沢 忠正, 納村 晋吉: Dept. of Orthodontics, Nihon Univ. School of Dentistry. The paper is to be read before the General Session of Japan Society of Orthodontics, to be held in Osaka, October, 1963. 
2. Measurements of the curves of Spee in the subjects.

For measurement purposes, a measuring apparatus devised by Prof. Masatoshi Arita was employed (Figs. 2 and 3). The standard plane is housed inside the apparatus and by aligning an imaginary occlusal plane on a given model in line with this standard plane thus set, one could determine a distance between a given imaginary occlusal plane and the buccal cusp of each tooth.

3. When the position of each cusp on the buccal side was indicated as negative $(-)$, it fell below the imaginary occlusal plane, while what was above the plane was. indicated as positive $(+)$.

4. In connection with the measurement of curves of Spee, distance between the buccal cusps of each tooth was measured by means of a divider.

Fig. 2

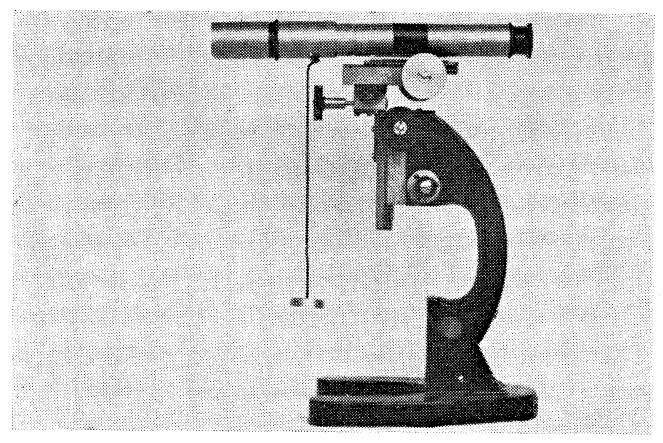

Fig. 3

Inside View of Measuring Apparatus

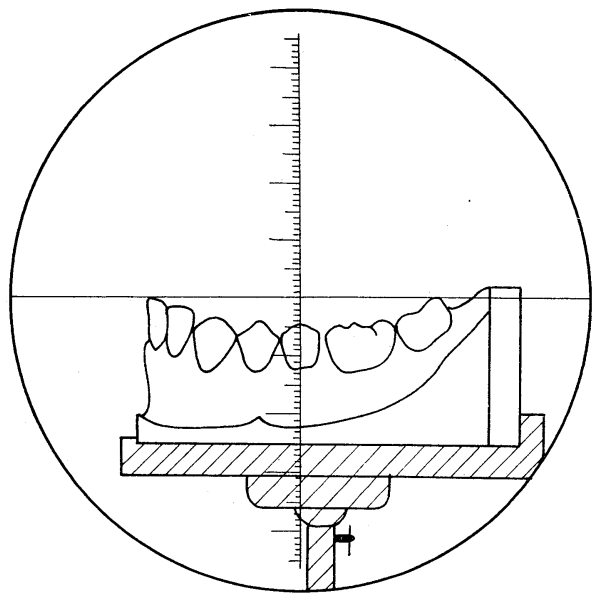

\section{Results}

Two sets of imaginary occlusal planes were established; one running from the tip of lower central incisor to the distal buccal cusp of lower 2nd molar and the other from the tip of lower central incisor to the distal buccal cusp of lower 1st. 
molar, and measurement was taken on a distance between each of the occlusal planes and the buccal cusp of each tooth. Mean values are given on Tables 1 and 2 .

These values are converted into curves and standard deviation graph as in Figs. 4 and 5 .

TABLE 1

Measurement of Spee's Curves in Persons of Normal Occlusion

Imaginary occlusal plane: Distal buccal cusp of lower 2nd molar

- Lower central incisor

\begin{tabular}{c|c|c|c}
\hline & & $\mathrm{N}=60$ \\
\hline $\begin{array}{c}\text { Mesial buccal cusp of } \\
\text { lower 2nd molar }\end{array}$ & Mean & S. E. & S. D. \\
\hline $\begin{array}{c}\text { Distal buccal cusp of } \\
\text { lower 1st molar }\end{array}$ & -0.83 & 0.04 & 0.33 \\
\hline $\begin{array}{c}\text { Mesial buccal cusp of } \\
\text { lower 1st molar }\end{array}$ & -1.47 & 0.08 & 0.65 \\
\hline $\begin{array}{c}\text { Buccal cusp of lower } \\
\text { 2nd premolar }\end{array}$ & -1.73 & 0.08 & 0.63 \\
\hline $\begin{array}{c}\text { Buccal cusp of lower } \\
\text { 1st premolar }\end{array}$ & -1.40 & 0.09 & 0.66 \\
\hline
\end{tabular}

Unit in $\mathrm{mm}$.

TABLE 2

Measurement of Spee's Curves in Persons of Normal Occlusion

Imaginary occlusal plane: Distal buccal cusp of lower 1st molar

-Lower central incisor

$\mathrm{N}=60$

\begin{tabular}{c|c|c|c}
\hline \hline & Mean & S. E. & S. D. \\
\hline $\begin{array}{c}\text { Mesial buccal cusp of } \\
\text { lower 1st molar }\end{array}$ & -0.54 & 0.05 & 0.38 \\
\hline $\begin{array}{c}\text { Buccal cusp of lower } \\
\text { 2nd premolar }\end{array}$ & -0.47 & 0.06 & 0.49 \\
\hline $\begin{array}{c}\text { Buccal cusp of lower } \\
\text { 1st premolar }\end{array}$ & -0.16 & 0.08 & 0.61 \\
\hline
\end{tabular}

Unit in $\mathrm{mm}$.

\section{Summary}

Our measurements on the curve of Spee in the Japanese of normal occlusion may be summarized as follows.

1) When an imaginary occlusal plane was established to run from the tip of lower central incisor to the distal buccal cusp of lower 2nd molar, curve of Spee was observed to increase from lower 1st premolar to lower 2nd premolar, the mesial buccal cusp of lower 1st molar being most prominent with $-1.73 \mathrm{~mm}$. This curve had a tendency to incline gradually from this point upward.

2) When an imaginary occlusal plane was established to run from the tip of lower central incisor to the distal buccal cusp of lower 1st molar curve of Spee has been observed to show the same tendency as in the above case, the mesial buccal cusp of lower 1st molar being most prominent with $-0.54 \mathrm{~mm}$. 
Fig. 4. Curves of Spee in Persons of Normal Occlusion (Unit in $\mathrm{mm}$ )

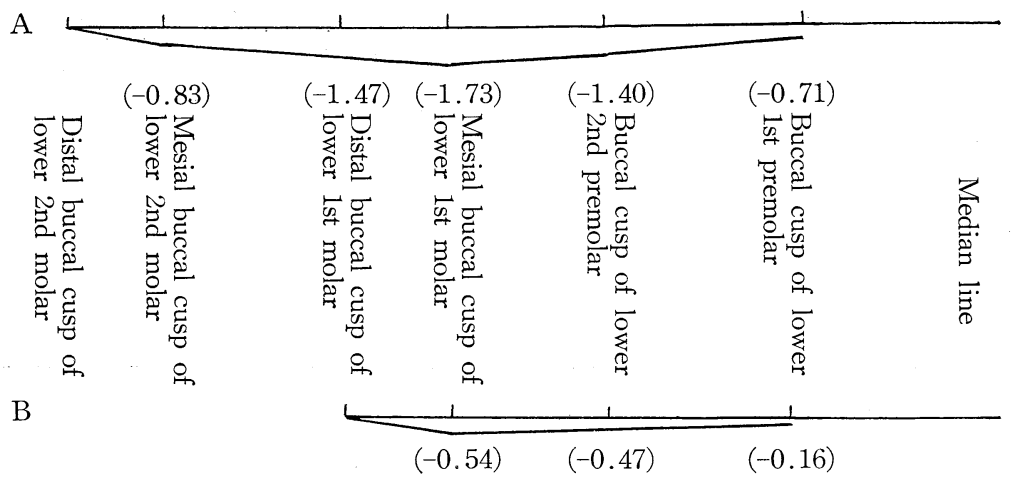

A : Imaginary occlusal plane based on the tip of lower central incisor to distal buccal cusp of lower 2nd molar

B : Imaginary occlusal plane based on the tip of lower central incisor to distal buccal cusp of lower 1st molar

Fig. 5



3) Two sets of Spee's curves obtained on the two imaginary occlusal planes: described above, were not sharp curves. But they were more or less in conformity with the occlusal planes thus established, being particularly true of a case where the imaginary plane ran from the tip of lower central incisor to the distal buccal cusp of lower 1st molar. In the latter case, it was more like a straight line than a curve in nature. For this reason, it may be considered that the so-called curve of Spee will become pronounced upon the eruption of lower second and third molars. This fact should be always borne in mind when an orthodontist undertakes a diagnosis in his. daily routine.

4) There was no significant difference on the right from the left side of dental arch, nor in terms of sex. 